\title{
The contribution of the ABCG2 C421A polymorphism to cancer susceptibility: a meta-analysis of the current literature
}

\author{
Pin Chen ${ }^{1 \dagger}$, Lin Zhao ${ }^{1 \dagger}$, Peng Zou ${ }^{1}$, Haitao Xu' ${ }^{1}$ Ailin Lu ${ }^{1}$ and Peng Zhao ${ }^{1,2^{*}}$
}

\begin{abstract}
Background: $A B C G 2$, also known as BCRP, is a half ATP-binding cassette $(A B C)$ transporter that localizes to plasma membranes. Recently, a number of studies have investigated the relationship between the C421A polymorphism in ABCG2 and cancer risk in multiple populations and various types of cancers; however, this relationship remains unclear. Therefore, we performed a meta-analysis to further explore this association.
\end{abstract}

Methods: The meta-analysis incorporated 10 studies involving a total of 3593 cases and 5875 controls. Odds ratios (ORs) and $95 \%$ confidence intervals (Cls) were calculated based on the date extracted from the studies to evaluate the strength of association. We also analyzed the heterogeneity and sensitivity of each report and the publication bias of the studies.

Results: Overall, our results showed that there appeared to be a significant association between the ABCG2 C421A polymorphism and decreased cancer susceptibility (heterozygote-AC versus CC: $\mathrm{OR}=0.759,95 \% \mathrm{Cl}=0.620-0.930$; dominant effects model-AA/AC versus CC: $\mathrm{OR}=0.771,95 \% \mathrm{Cl}=0.634-0.938$; additive effects model-A allele versus $C$ allele: $\mathrm{OR}=0.809,95 \% \mathrm{Cl}=0.687-0.952$ ). Similarly, decreased cancer risk was also found after stratification of the SNP data by cancer type, ethnicity and source of controls in heterozygote model, dominant effects model and additive effects model.

Conclusions: We found that the ABCG2 C421A polymorphism is a protective factor for developing cancer. The same relationship was found when the studies were stratified by cancer type, ethnicity and source of controls.

\section{Background}

Cancer is a multi-factorial disease, which results from complex interactions between environmental and genetic factors, has become one of the most challenging health issues today [1]. In contrast to environmental variables, the genetic variables ranging from single-nucleotide substitutions to major chromosomal aberrations may make more contribution to the cancer development [2,3]. In the last few years, an increasing number of studies have been conducted to assess the relationship between the hereditary factors and cancer risk.

$\mathrm{ABC}$ transporters, or the family of adenosine triphosphate (ATP) binding cassette are a large superfamily of

\footnotetext{
* Correspondence: zhaopeng@njmu.edu.cn

${ }^{\dagger}$ Equal contributors

'Department of neurosurgery, the First Affiliated Hospital, Nanjing Medical University, Nanjing, China

${ }^{2}$ The First Affiliated Hospital of Nanjing Medical University, 300 Guangzhou Road, Nanjing 210029, China
}

C Biomed Central

(c) 2012 Chen et al.; licensee BioMed Central Ltd. This is an Open Access article distributed under the terms of the Creative Commons Attribution License (http://creativecommons.org/licenses/by/2.0), which permits unrestricted use, distribution, and reproduction in any medium, provided the original work is properly cited.

transmembrane glycoprotein and contain over 50 members which can mediate the transfer of a wide variety of substrates across cellular membranes [4]. ATP-binding cassette G2 (ABCG2), originally known as Breast Cancer Resistant Protein (BCRP), first discovered in doxorubicin-resistant breast cancer cells is a major member of the ATP-binding cassette transporter family and located on chromosomal region 4q22 encoding a $72-\mathrm{kDa}$ membrane protein $[5,6]$. It is constitutively expressed in various tissues such as the embryonic stem cells, placental syncytiotrophoblasts, pancreas, liver, gastrointestinal, muscle and immature hematopoietic tissues [7-9]. Previous functional researches reviewed that ABCG2 can transport a wide spectrum of substrates, ranging from chemotherapeutic agents to carcinogenic xenobiotics [10-13]. ABCG2 may play an important role in controlling the cellular export of xenobiotic molecules. The differential metabolism of xenobiotics due to 
variations in the transporter molecules may affect the risk of some cancers [14-18].

It has been recognized that single nucleotide polymorphisms (SNPs) are the most common inherited sequence variations in the human genome. These polymorphisms can change the expression and activity of the corresponding genes and their proteins and affect the susceptibility to different types of cancers [19-23]. Researches had shown that there were two frequently polymorphic SNPs in the BCRP gene: one in exon2 (G34A, resulting in a V12M change) and the other in exon5 (C421A, resulting in a Q141K substitution) respectively [15]. The C421A polymorphism (rs2231142) in ABCG2 which lead to a glutamine-to-lysine amino acid substitution is found at different frequencies in different ethnic populations (Asians: 35\%, Caucasians: 10\%) and is apparently correlated with the reduced expression and activity of BCRP protein [21,24-26].

To date, numerous studies have investigated the association between the C421A polymorphism in ABCG2 and the cancer susceptibility. Unfortunately, however, the results of these studies have been inconsistent. Therefore, in order to gain insights into the association between polymorphism of ABCG2 C421A and cancer risk, we conducted a meta-analysis of eligible case-control and cohort studies.

\section{Methods}

\section{Study eligibility and validity assessment}

We conducted a systematic search in PubMed and Embase (last updated on February 10, 2012) using the terms "(ABCG2 or BCRP) and polymorphism "without any restriction in language and publication year. To identify other relevant studies, the articles cited by the retrieved studies were also searched. Each of the selected articles in our meta-analysis met all of the following criteria: 1) the article pertained to the ABCG2 C421A polymorphism and cancer risk; 2) the design was a human case-control or case-cohort study; and 3) the genotype frequencies in the cancer cases and controls were available. Studies were excluded if they did not include a control population, did not determine genotype frequency and or were duplicates of previous publications.

\section{Data extraction}

The data were extracted from all eligible studies that met the selection criteria listed above. The data extraction was performed by two authors independently and any disagreements were resolved by discussion between the two authors. The data collected from each study were as follows: the first author's name, publication year, country of origin, ethnicity, cancer type, control groups source, number of cases and controls, and genotype frequencies for cases and controls. The deviation of the genotype frequencies in the control populations from Hardy-Weinberg Equilibrium (HWE) was calculated separately for each study. The control group sources were classified as population-based controls, hospitalbased controls or mixed (both population- and hospitalbased) controls. The population ethnicity was classified as Asian or Caucasian.

\section{Statistical analysis}

We conducted all statistical analyses using STATA software (version 11; Stata Corporation, College Station, Texas). All $\mathrm{P}$-values were two-sided and $\mathrm{P}<0.05$ was considered statistically significant. Odds ratios (ORs) and $95 \%$ confidence intervals (CIs) were calculated to assess the strength of the association between the ABCG2 C421A polymorphism and the cancer risk. We also examined the overall association of the A allele of C421A with risk of cancers and compared cancer incidence in homozygote (AA versus $\mathrm{CC}$ ) model and heterozygotes (AC versus $\mathrm{CC}$ ) model, dominant (AC/AA versus $\mathrm{CC}$ ) model and the recessive (AA versus $\mathrm{CC} / \mathrm{AC}$ ) model. The values for ORs and CIs of each individual were considered twice. Stratified analyses were conducted by cancer type, source of controls and ethnicity. The Hardy-Weinberg equilibrium was calculated for all the control groups of each study, and control groups of studies that were not in HWE $(\mathrm{p}<0.05)$ were excluded. A chi-squared-based Q-statistic test was used to detect the heterogeneity among studies. When the P-value of the Q-test was $>0.05$, which indicated a lack of heterogeneity among studies, a fixed-effects model (the Mantel-Haenszel method) was used [27]. Otherwise, if the $P$-value $<0.05$, the random-effects model (the DerSimonian and Laird method) was used [28]. The $\mathrm{Z}$ test was used to determine the significance of the combined OR and $\mathrm{P}<0.05$ was considered statistically significant.

Sensitivity analyses to evaluate the possible biases of the results in our meta-analyses were also performed. In addition, we assessed the potential publication bias with funnel plots of the effect sizes versus the standard errors and identified the significant asymmetry by the Begg's test. An asymmetric plot suggests possible publication bias. If the $P$ value $<0.05$, the publication bias was considered significantly.

\section{Results}

\section{Studies selected}

The meta-analysis included 8 eligible articles comprising 9 case-control studies and 1 case-cohort study, for a total of 3593 cases and 5875 controls. The study selection procedure is showed in Figure 1 and the study characteristics are displayed in Table 1 [29-36]. Among all 10 studies, 2 focused only on colorectal cancer, 3 focused on lymphoma, 3 focused on leukemia and 2 focused on 


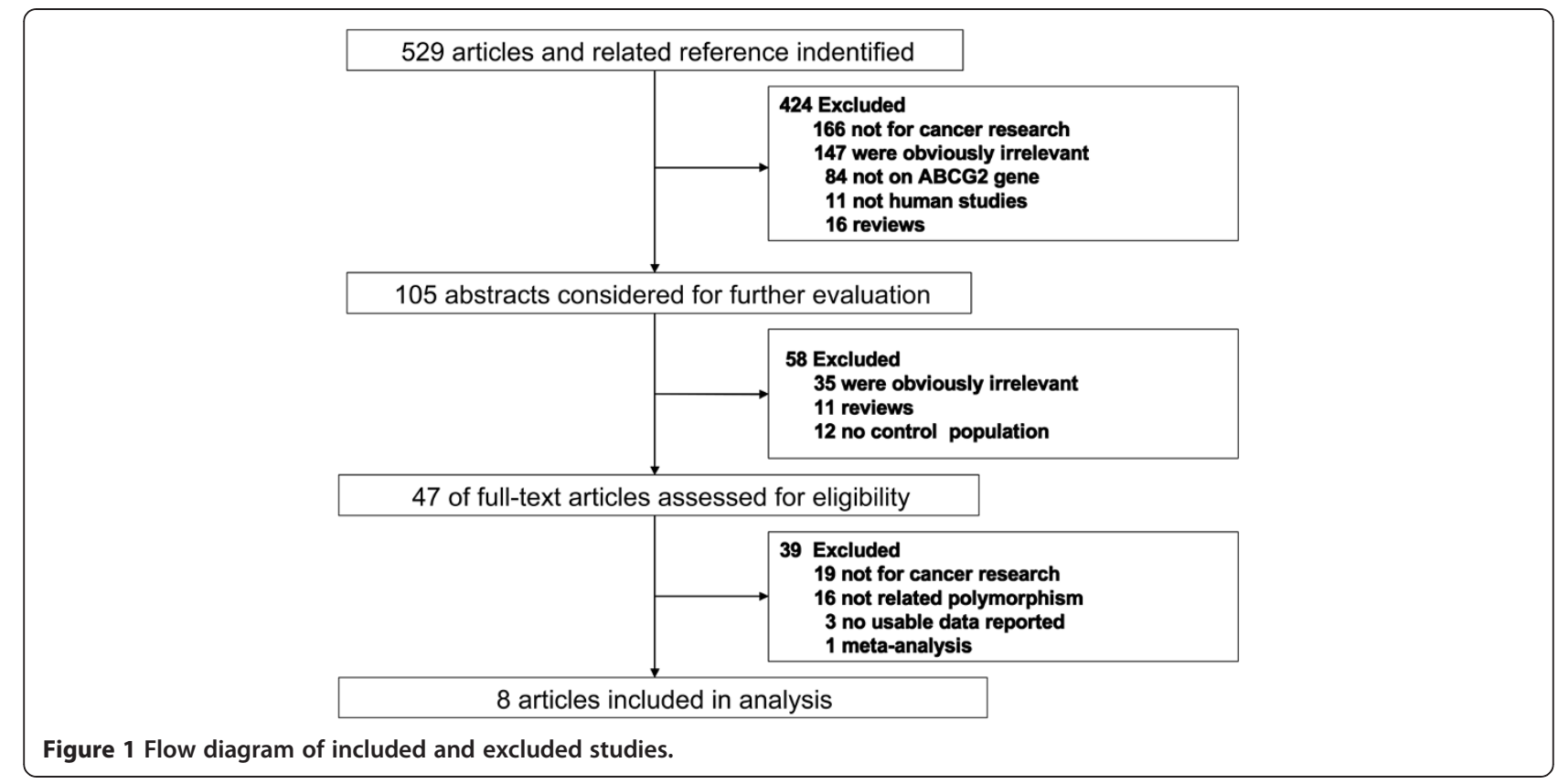

other cancers. Among the 10 eligible studies, 8 studies were conducted in Caucasian populations, and 2 studies were conducted in Asian populations. The control sources were population-based in 3 studies, hospitalbased in 6 studies and both population-based and hospital-based in 1 study. The genotype frequency data for the C421A polymorphism in ABCG2 were extracted from all the eligible studies, and the distributions of the genotypes in the control populations were consistent with Hardy-Weinberg equilibrium in all of the studies.

\section{Quantitative data synthesis}

Overall, there was evidence for an association between decreased cancer risk and the variant genotypes in different genetic models and the results were listed in
Table 2 and Figure 2. A significant decreased association between the ABCG2 C421A genotype and cancer risk was observed in our meta-analysis of the 10 studies (heterozygote model $-\mathrm{AC}$ versus $\mathrm{CC}: \mathrm{OR}=0.759,95 \% \mathrm{CI}=$ 0.620-0.930; dominant effects model-AA/AC versus CC: $\mathrm{OR}=0.771,95 \% \mathrm{CI}=0.634-0.938$; additive effects modelA allele versus $C$ allele: $\mathrm{OR}=0.809,95 \% \mathrm{CI}=0.687$ 0.952).

The same association was discovered in the subgroup analyses. In the subgroup analysis by cancer types, the ABCG2 C421A genotype significantly reduced the risk of leukemia and other cancers in additive model (OR = $0.741,95 \% \mathrm{CI}=0.577-0.951 ; \mathrm{OR}=0.669,95 \% \mathrm{CI}=0.511$ 0.876). Meanwhile, the variant heterozygote homozygote genotype AC was associated with significantly decreased

Table 1 Characteristics of studies included in the meta-analysis

\begin{tabular}{lllllllllllllllll}
\hline First author & Year & Country & Ethnicity & Cancer type & $\begin{array}{l}\text { Source of } \\
\text { Controls }\end{array}$ & Cases & Controls & Case & & & Control & HWE \\
\hline & & & & & & & CC & CA & AA & CC & CA & AA \\
\hline Andersen[29] & 2009 & Denmark & Caucasian & Colorectal cancer & PB & 359 & 765 & 296 & 58 & 5 & 592 & 161 & 12 & 0.782 \\
\hline Campa[31] & 2008 & Germany & Caucasian & Colorectal cancer & HB & 582 & 517 & 472 & 103 & 7 & 409 & 104 & 4 & 0.347 \\
\hline Campa[30] & 2011 & Germany & Caucasian & Lymphoma & HB & 1067 & 1196 & 898 & 158 & 11 & 957 & 229 & 10 & 0.359 \\
\hline Campa[30] & 2011 & Germany & Caucasian & Lymphoma & HB & 259 & 1156 & 224 & 33 & 2 & 921 & 221 & 14 & 0.856 \\
\hline Hu[33] & 2007 & China & Asian & Lymphoma & MIXED & 156 & 376 & 60 & 80 & 16 & 181 & 162 & 33 & 0.703 \\
\hline Campa[30] & 2011 & Germany & Caucasian & Leukemia & HB & 321 & 1196 & 284 & 33 & 4 & 957 & 229 & 10 & 0.359 \\
\hline Muller[35] & 2008 & Germany & Caucasian & Leukemia & HB & 110 & 179 & 100 & 10 & 0 & 160 & 18 & 1 & 0.532 \\
\hline Semsei[36] & 2008 & Hungary & Caucasian & Leukemia & HB & 369 & 149 & 294 & 72 & 3 & 121 & 28 & 0 & 0.206 \\
\hline Korenaga[34] & 2005 & Japan & Asian & Renal cell carcinoma & PB & 200 & 200 & 124 & 60 & 16 & 92 & 91 & 17 & 0.405 \\
\hline Gardner[32] & 2008 & America & Caucasian & Prostate cancer & PB & 170 & 141 & 142 & 27 & 1 & 111 & 27 & 3 & 0.384 \\
\hline
\end{tabular}

PB: population based; HB: hospital based; MIXED: population based and hospital based. 
Table 2 Total and stratified analysis of ABCG2 C421A polymorphism on cancer risk

\begin{tabular}{|c|c|c|c|c|c|c|c|c|c|c|}
\hline \multirow[t]{2}{*}{ Variables } & \multicolumn{2}{|c|}{$A A$ versus $C C$} & \multicolumn{2}{|l|}{$A C$ versus $C C$} & \multicolumn{2}{|l|}{$A$ versus $C$} & \multicolumn{2}{|c|}{ Recessive model } & \multicolumn{2}{|c|}{ Dominant model } \\
\hline & OR(95\%Cl) & $P^{a}$ & OR(95\%Cl) & $p^{a}$ & OR(95\%Cl) & $p^{a}$ & OR(95\%Cl) & $P^{a}$ & OR(95\%Cl) & $P^{a}$ \\
\hline Total & $1.021(0.730-1.428)$ & 0.784 & $0.759(0.620-0.930)^{b}$ & 0.004 & $0.809(0.687-0.952)^{b}$ & 0.013 & $1.067(0.768-1.482)$ & 0.935 & $0.771(0.634-0.938)^{b}$ & 0.005 \\
\hline \multicolumn{11}{|l|}{ Cancer type } \\
\hline colorectal cancer & $1.073(0.491-2.344)$ & 0.470 & $0.791(0.633-0.988)$ & 0.445 & $0.840(0.688-1.025)$ & 0.353 & $1.127(0.516-2.462)$ & 0.494 & $0.806(0.649-1.001)$ & 0.388 \\
\hline lymphoma & $1.200(0.736-1.958)$ & 0.541 & $0.867(0.544-1.381)^{b}$ & 0.003 & $0.874(0.600-1.273)^{b}$ & 0.004 & $1.113(0.692-1.791)$ & 0.724 & $0.875(0.552-1.385)^{b}$ & 0.002 \\
\hline leukemia & $1.371(0.507-3.704)$ & 0.750 & $0.744(0.426-1.299)^{b}$ & 0.038 & $0.741(0.577-0.951)$ & 0.072 & $1.474(0.543-4.002)$ & 0.752 & $0.762(0.451-1.290)^{b}$ & 0.049 \\
\hline other & $0.627(0.314-1.251)$ & 0.419 & $0.574(0.407-0.808)$ & 0.205 & $0.669(0.511-0.876)$ & 0.827 & $0.822(0.420-1.607)$ & 0.309 & $0.582(0.420-0.807)$ & 0.347 \\
\hline \multicolumn{11}{|l|}{ Source of control } \\
\hline Population based & $0.684(0.383-1.223)$ & 0.661 & $0.647(0.510-0.821)$ & 0.289 & $0.710(0.582-0.867)$ & 0.800 & $0.840(0.477-1.480)$ & 0.594 & $0.654(0.520-0.823)$ & 0.406 \\
\hline Hospital based & $1.155(0.683-1.954)$ & 0.897 & $0.721(0.627-0.829)$ & 0.127 & $0.780(0.687-0.885)$ & 0.158 & $1.225(0.724-2.075)$ & 0.904 & $0.739(0.645-0.847)$ & 0.133 \\
\hline $\mathrm{HB}+\mathrm{PB}$ & - & & & & - & & - & & - & \\
\hline \multicolumn{11}{|l|}{ Ethnicity } \\
\hline Asian & $1.040(0.633-1.707)$ & 0.143 & $0.856(0.287-2.549)^{b}$ & 0.000 & $0.923(0.478-1.784)^{b}$ & 0.002 & $1.069(0.666-1.715)$ & 0.623 & $0.882(0.317-2.457)^{b}$ & 0.000 \\
\hline Caucasian & $1.006(0.637-1.587)$ & 0.846 & $0.723(0.638-0.820)$ & 0.280 & $0.773(0.690-0.866)$ & 0.320 & $1.065(0.675-1.682)$ & 0.849 & $0.737(0.652-0.833)$ & 0.293 \\
\hline
\end{tabular}

${ }_{\mathrm{a}} \mathrm{P}$ value of Q-test for heterogeneity test.

${ }^{\mathrm{b}}$ Random-effects model was used when $\mathrm{P}$ value for heterogeneity test $<0.05$; otherwise, fix-effects model was used. 


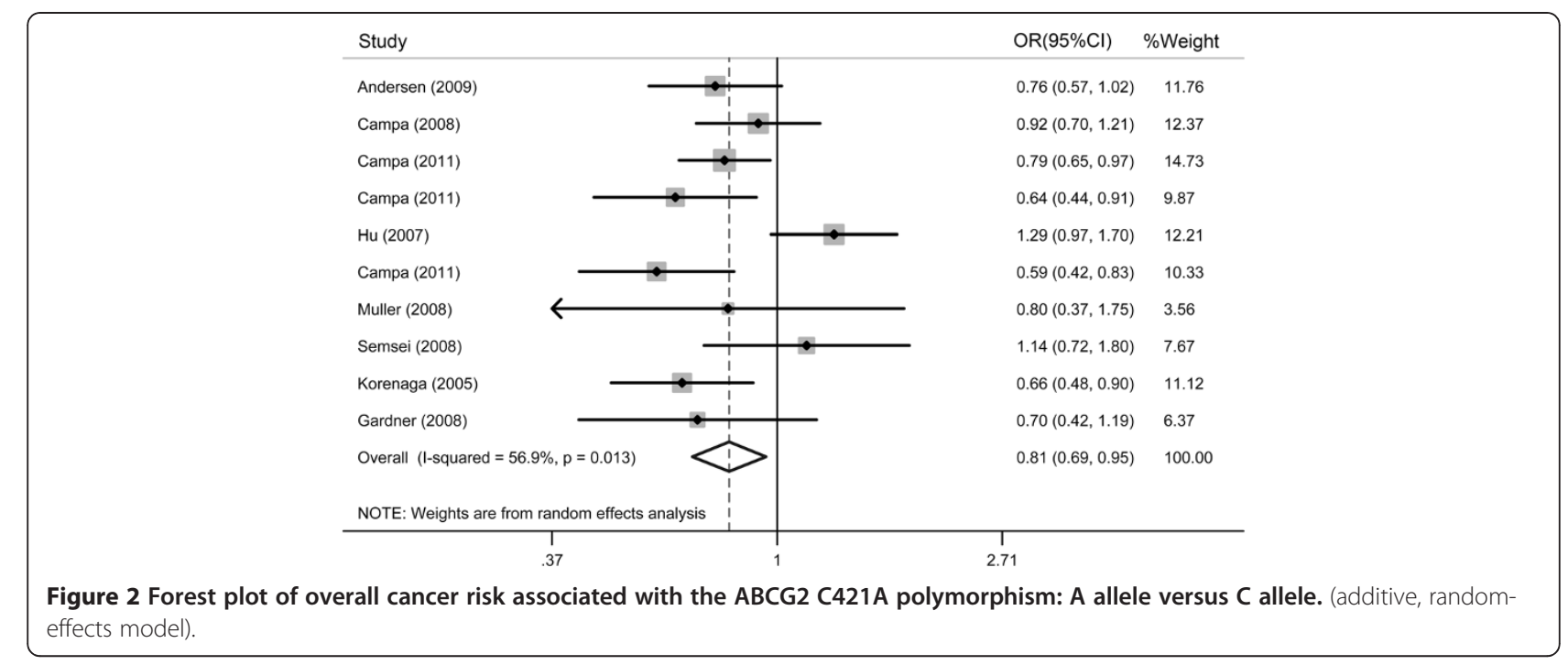

colorectal cancer risk (heterozygote model-AC versus $\mathrm{CC}: \mathrm{OR}=0.791,95 \% \mathrm{CI}=0.633-0.988)$ compared with the wild-type homozygote genotype CC; When the studies were stratified by the source of controls, associations were observed in both studies with population-based controls $(\mathrm{OR}=0.710,95 \% \mathrm{CI}=0.582-0.867)$ and those with hospital-based controls $(\mathrm{OR}=0.780,95 \% \mathrm{CI}=0.687$ 0.885). In the dominant effects model and heterozygote model, this association was also present and the result was listed in Table 2; In the analysis stratified by population, the C421A polymorphism in ABCG2 was significantly correlated with cancer risk in Caucasian populations $(\mathrm{OR}=0.773,95 \% \mathrm{CI}=0.690-0.866)$ but not in Asian populations $(\mathrm{OR}=0.923, \quad 95 \% \mathrm{CI}=0.478-1.784)$ populations in additive genetic model, however, in the dominant effect model and heterozygote model, no significant association between the ABCG2 polymorphism and low cancer risk was found in Asian in comparison to in Caucasian and the result was presented listed in Table 2.

\section{Heterogeneity analysis}

There was significant heterogeneity among studies in the additive model, dominant effect model and heterozygote model $(2 \mathrm{AA}+\mathrm{AC}$ versus $2 \mathrm{CC}+\mathrm{AC}, \mathrm{AA}+\mathrm{AC}$ versus $\mathrm{CC}$, $A C$ versus $C C$ ) of the C421A polymorphism in ABCG2. However, in the other model comparisons (AA versus $\mathrm{CC}, \mathrm{AA}$ versus $\mathrm{AC} / \mathrm{CC}$ ), heterogeneity was not found (Table 2). We assessed additive model comparison, heterozygote comparison and dominant model comparison

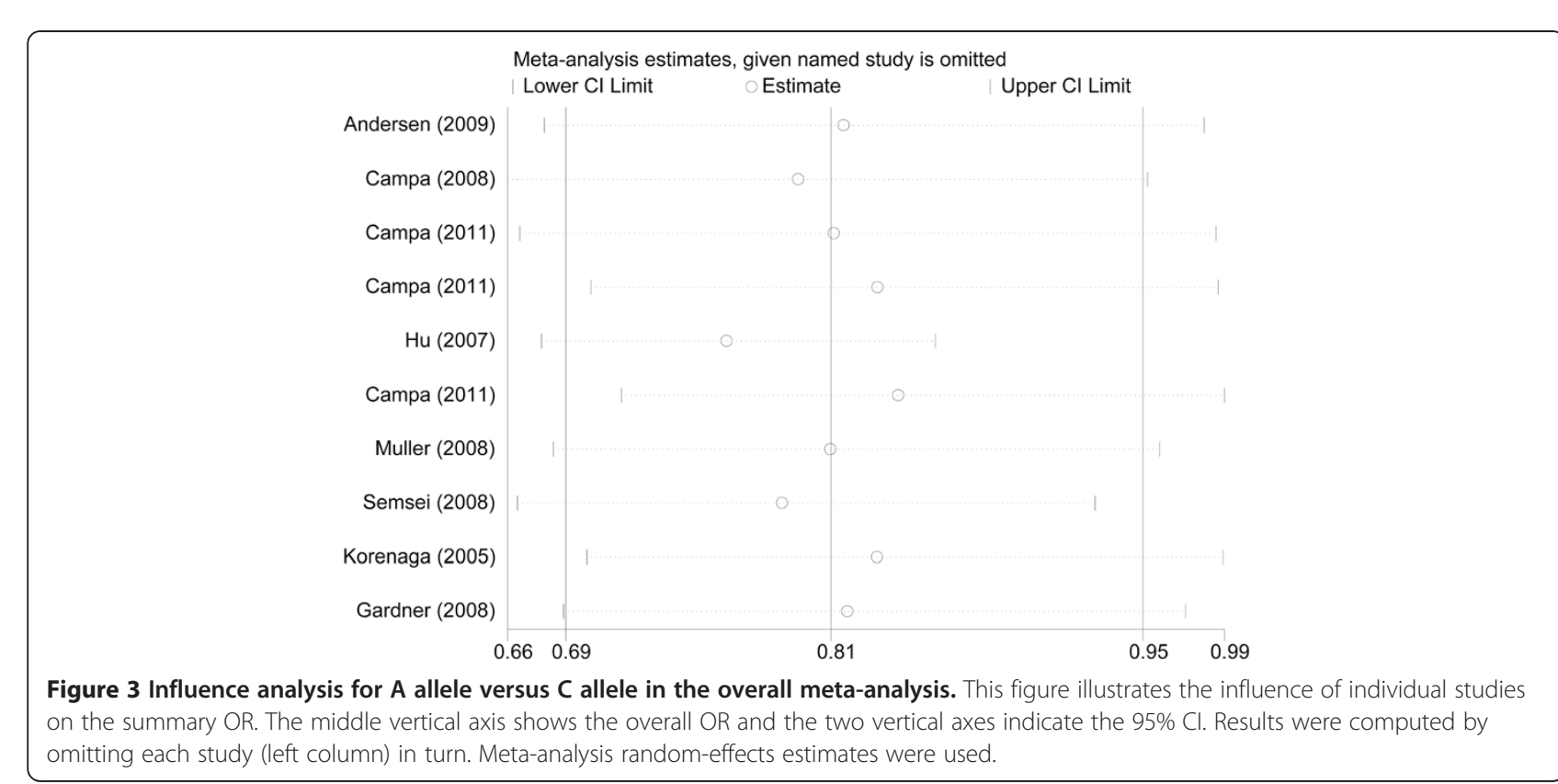




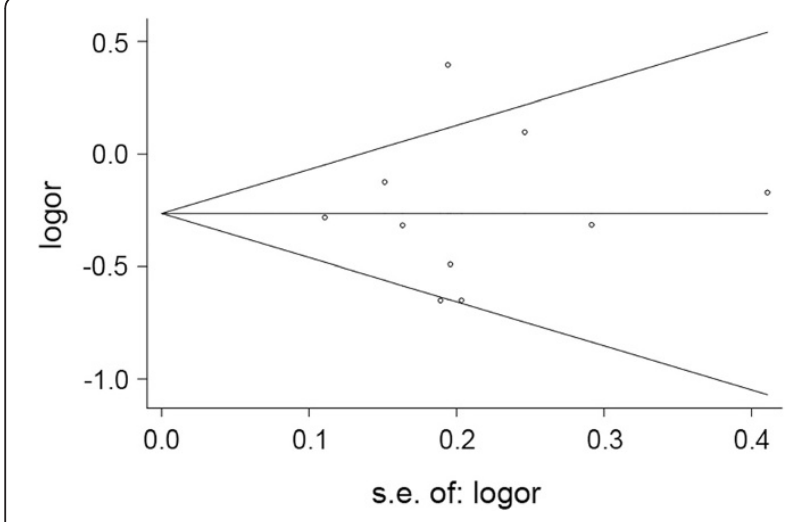

Figure 4 Begg's funnel plot for publication bias test (AA/AC VS CC); each point represents a separate study for the indicated association. Log(OR): natural logarithm of OR. Horizontal line represents size of effect.

by tumor type, ethnicity, publication year, control source, sample size and HWE in controls. However, we did not observe any contribution to the substantial heterogeneity.

\section{Sensitivity analyses}

We performed sensitivity analyses by sequentially removing individual eligible study (Figure 3 ). The results indicated that the overall significance of the ORs was not altered by any single study in the genetic models for the C421A polymorphism in ABCG2 and cancer susceptibility which suggested the stability and liability of our overall results.

\section{Publication bias}

We assessed the potential publication biases of the included studies using the Begg's funnel plot and Egger's test (Figure 4), the result showed no significant evidence of publication bias $(t=0.15, \mathrm{P}=0.884$ for dominant effects model).

\section{Discussion}

Carcinogenesis is a complex process that involves both genetic and environmental factors and their interactions [1]. Since the genetic factors such as single nucleotide substitutions and gross chromosomal aberrations were considered to make more contribution to tumorigenesis, numerous studies focused on the candidatepolymorphism approach notably increased the number of associations between polymorphism and cancer risk [37]. Recently, increasing attention has been paid to the relationships between genetic variants such as SNPs and cancer risk. Plentiful epidemiological evidence demonstrated that the process of detoxification and elimination of xenobiotics was involved in the development of cancers $[14,16,17]$.
The ABCG2 gene (also known as BCRP), located on chromosomal locus 4q22, encodes an $A B C$ halftransporter protein that localizes to the plasma membrane. ABCG2 works as a multidrug efflux pump, influencing the metabolism of multiple substances including anticancer drugs and carcinogenic xenobiotics [10-13]. The abnormal distribution of carcinogenic xenobiotics may increase the local carcinogen burden of specific cells and organelles [38] and cause tumorigenesis. To date, there have been a great deal of epidemiological studies to investigate the association between the C421 polymorphism in ABCG2 and the risk of various types of cancers, however, the exact relationship between cancer susceptibility and the ABCG2 C421A polymorphism remains unclear. To address this issue, we performed a synthetic analysis based on data collected from all studies that have investigated the relationship between this polymorphism and cancer risk.

Generally speaking, our meta-analysis, which included 3593 cases and 5875 controls, revealed a significant association between the ABCG2 C421A allele and decreased cancer risk in different genetic model (heterozygote model- $\mathrm{AC}$ versus $\mathrm{CC}$ : $\mathrm{OR}=0.759,95 \% \mathrm{CI}=0.620$ 0.930; dominant effects model-AA/AC versus CC: $\mathrm{OR}=$ 0.771, 95\% CI =0.634-0.938; additive effects model-A allele versus $C$ allele: $\mathrm{OR}=0.809,95 \% \mathrm{CI}=0.687-0.952$ ). This result provides convincing evidence that the C421A polymorphism in ABCG2 might protect against cancer development. Moreover, this effect persisted when the studies were stratified by ethnicity classification. When stratified by cancer, source of controls and ethnicity classification, the C421A polymorphism of ABCG2 was also an important protective factor against cancer development in the subgroups studied.

However, the studies published by $\mathrm{Hu}$ and Korenaga $[33,34]$ were contradictory to ours, indicating that carriers of the A allele of ABCG2 C421A had an increased risk of cancer. Three explanations may have contributed to this disparity in results. One possible explanation could be that the different environmental factors or different sample size of the two studies may influence the function of the ABCG2 C421A for developing cancer. Another possible explanation for this observation was that gene-gene interactions and gene-environment interactions may be responsible for this discrepancy. Moreover, the overlapping function of the other $A B C$ transporters may be involved in. However, the precise mechanism of the contradictory effect remains unsure, further studies may help to clarify this issue.

It is well known that four capital factors of genomewide association studies (GWAS) consisting of models of the allelic architecture of common diseases, sample size, map density and sample-collection biases need to be taken into account in order to optimize the cost 
efficiency of identifying precise disease-susceptibility loci [39]. To validate the strong associations between the C421A polymorphism in ABCG2 and the cancer risk, Daniele Campa and his colleagues extracted date from two previous GWAS on CLL (chronic lymphocytic leukemia) $[40,41]$. Based on the genotyping information from them, allelic odds ratios were calculated to confirm the relationship between the genetic polymorphisms and CLL risk. Their results identified a statistically significant association between the risk of CLL and the ABCG2 C421A genotype [30]. Furthermore, these authors also performed a meta-analysis of 3 studies [30,40,41], which provided evidence of a significant association between decreased cancer risk and the ABCG2 C421A polymorphism. Our findings were consistent with these results [30].

Heterogeneity is a potential problem which might influence the interpretation of the results. In our metaanalysis, significant heterogeneity between studies was present in additive model, heterozygote model and dominant model (Table 2). The heterogeneity reduced or disappeared when the studies were stratified by cancer type, source of controls and ethnicity, however, we did not find adequate evidence to determine which of them contributed most to the substantial heterogeneity. The publication bias for the association between this polymorphism and cancer risk was not observed in our meta-analysis.

Some possible limitations of our meta-analysis should be acknowledged and taken into consideration. First, detailed information, such as the mean age and sex of the case and control populations, was not available in all of the selected studies, which limited further analyses. Second, the results may be influenced by the lack of observations regarding gene-gene and gene-environment interactions even different polymorphic loci of the same gene. Third, the conclusions had the possibility to be disturbed due to the existence of overlapping function of the other $\mathrm{ABC}$ transporters. Fourth, the numbers of published studies were not sufficiently enough for a comprehensive analysis on different types of cancer. For example, there were no published data for gastric cancer, nervous system neoplasm and lung cancer with association of ABCG2 C421A published up to now; we did not posses enough statistical power to detect the precise association. More studies are needed to explore the relationship between C421A polymorphism in ABCG2 and cancer risk. In spite of these potential limitations, our meta-analysis also has many advantages. Firstly, sufficient date was extracted form well-selected studies, providing good statistical power for this meta-analysis. Secondly, studies included in our meta-analysis contained available genotype frequency and the distribution of the genotypes in the control population of all the studies were consistent with Hardy-Weinberg equilibrium. Thirdly, no publication bias was detected among the pooled results.

\section{Conclusions}

In conclusion, this meta-analysis demonstrates that the ABCG2 C421A polymorphism is associated with a decreased risk of cancer and is likely a protective factor against cancer development. However, further studies on the relationship between this polymorphism and cancer risk are warranted.

\section{Competing interests}

The authors declare that there are no competing interests.

\section{Authors' contributions}

PC participated in collection of data and manuscript preparation. LZ, PZ and HX performed the statistical analysis. PZ participated in study design and critically revised the manuscript. PZ and AL participated in study design and manuscript preparation All authors read and approved the final manuscript.

\section{Acknowledgements}

We thank Dr. Meilin Wang for the scientific design. This work is supported by the National Natural Science Foundation of China (grant 30901534 and 81172694); the Jiangsu Province's Natural Science Foundation (Proj. no. BK2009444); the Grant for the 135 Key Medical Project of Jiangsu Province (No. XK201117); and the National high technology research and development program 863 (No. 2012AA02A508).

Received: 7 April 2012 Accepted: 27 August 2012

Published: 1 September 2012

\section{References}

1. Pharoah PD, Dunning AM, Ponder BA, Easton DF: Association studies for finding cancer-susceptibility genetic variants. Nat Rev Cancer 2004, 4 (11):850-860.

2. Bartsch H, Dally H, Popanda O, Risch A, Schmezer P: Genetic risk profiles for cancer susceptibility and therapy response. Recent Results Cancer Res 2007, 174:19-36.

3. Shiloh Y: ATM and related protein kinases: safeguarding genome integrity. Nat Rev Cancer 2003, 3(3):155-168.

4. Dean M, Allikmets R: Complete characterization of the human $A B C$ gene family. J Bioenerg Biomembr 2001, 33(6):475-479.

5. Bailey-Dell KJ, Hassel B, Doyle LA, Ross DD: Promoter characterization and genomic organization of the human breast cancer resistance protein (ATP-binding cassette transporter G2) gene. Biochim Biophys Acta 2001, 1520(3):234-241.

6. Doyle LA, Yang W, Abruzzo LV, Krogmann T, Gao Y, Rishi AK, Ross DD: A multidrug resistance transporter from human MCF-7 breast cancer cells. Proc Natl Acad Sci USA 1998, 95(26):15665-15670.

7. Lechner A, Leech CA, Abraham EJ, Nolan AL, Habener JF: Nestin-positive progenitor cells derived from adult human pancreatic islets of Langerhans contain side population (SP) cells defined by expression of the ABCG2 (BCRP1) ATP-binding cassette transporter. Biochem Biophys Res Commun 2002, 293(2):670-674.

8. Maliepaard M, Scheffer GL, Faneyte IF, van Gastelen MA, Pijnenborg AC, Schinkel AH, van De Vijver MJ, Scheper RJ, Schellens JH: Subcellular localization and distribution of the breast cancer resistance protein transporter in normal human tissues. Cancer Res 2001, 61(8):3458-3464

9. Zhou S, Schuetz JD, Bunting KD, Colapietro AM, Sampath J, Morris JJ, Lagutina I, Grosveld GC, Osawa M, Nakauchi H, et al: The ABC transporter Bcrp1/ABCG2 is expressed in a wide variety of stem cells and is a molecular determinant of the side-population phenotype. Nat Med 2001 , 7(9):1028-1034.

10. Krishnamurthy $P$, Schuetz JD: Role of ABCG2/BCRP in biology and medicine. Annu Rev Pharmacol Toxicol 2006, 46:381-410.

11. Maliepaard M, van Gastelen MA, Tohgo A, Hausheer FH, van Waardenburg RC, de Jong LA, Pluim D, Beijnen JH, Schellens JH: Circumvention of breast 
cancer resistance protein (BCRP)-mediated resistance to camptothecins in vitro using non-substrate drugs or the BCRP inhibitor GF120918. Clin Cancer Res 2001, 7(4):935-941.

12. Mao Q, Unadkat JD: Role of the breast cancer resistance protein (ABCG2) in drug transport. AAPS J 2005, 7(1):E118-133.

13. Sarkadi B, Ozvegy-Laczka C, Nemet K, Varadi A: ABCG2 - a transporter for all seasons. FEBS Lett 2004, 567(1):116-120.

14. Agundez JA: Polymorphisms of human $\mathrm{N}$-acetyltransferases and cancer risk. Curr Drug Metab 2008, 9(6):520-531.

15. Ambudkar SV, Dey S, Hrycyna CA, Ramachandra M, Pastan I, Gottesman MM: Biochemical, cellular, and pharmacological aspects of the multidrug transporter. Annu Rev Pharmacol Toxicol 1999, 39:361-398.

16. Leslie EM, Deeley RG, Cole SP: Toxicological relevance of the multidrug resistance protein 1, MRP1 (ABCC1) and related transporters. Toxicology 2001, 167(1):3-23.

17. Singh MS, Michael M: Role of xenobiotic metabolic enzymes in cancer epidemiology. Methods Mol Biol 2009, 472:243-264.

18. Watkins PB: The barrier function of CYP3A4 and P-glycoprotein in the small bowel. Adv Drug Deliv Rev 1997, 27(2-3):161-170.

19. Cargill M, Altshuler D, Ireland J, Sklar P, Ardlie K, Patil N, Shaw N, Lane CR, Lim EP, Kalyanaraman N, et al: Characterization of single-nucleotide polymorphisms in coding regions of human genes. Nat Genet 1999, 22 (3):231-238.

20. Gunderson KL, Kuhn KM, Steemers FJ, Ng P, Murray SS, Shen R: Wholegenome genotyping of haplotype tag single nucleotide polymorphisms. Pharmacogenomics 2006, 7(4):641-648.

21. Kobayashi D, leiri I, Hirota T, Takane H, Maegawa S, Kigawa J, Suzuki H, Nanba E, Oshimura M, Terakawa N, et al: Functional assessment of ABCG2 (BCRP) gene polymorphisms to protein expression in human placenta. Drug Metab Dispos 2005, 33(1):94-101.

22. Mcllwain CC, Townsend DM, Tew KD: Glutathione S-transferase polymorphisms: cancer incidence and therapy. Oncogene 2006, 25 (11):1639-1648.

23. Sai K, Kaniwa N, Itoda M, Saito Y, Hasegawa R, Komamura K, Ueno K, Kamakura S, Kitakaze M, Shirao K, et al: Haplotype analysis of ABCB1/MDR1 blocks in a Japanese population reveals genotype-dependent renal clearance of irinotecan. Pharmacogenetics 2003, 13(12):741-757.

24. Imai $Y$, Nakane M, Kage $K$, Tsukahara S, Ishikawa E, Tsuruo T, Miki Y, Sugimoto $Y$ : C421A polymorphism in the human breast cancer resistance protein gene is associated with low expression of Q141K protein and low-level drug resistance. Mol Cancer Ther 2002, 1(8):611-616.

25. Maeda K, Sugiyama Y: Impact of genetic polymorphisms of transporters on the pharmacokinetic, pharmacodynamic and toxicological properties of anionic drugs. Drug Metab Pharmacokinet 2008, 23(4):223-235.

26. Mizuarai S, Aozasa N, Kotani H: Single nucleotide polymorphisms result in impaired membrane localization and reduced atpase activity in multidrug transporter ABCG2. Int J Cancer 2004, 109(2):238-246.

27. Mantel N, Haenszel W: Statistical aspects of the analysis of data from retrospective studies of disease. J Natl Cancer Inst 1959, 22(4):719-748.

28. DerSimonian R, Laird N: Meta-analysis in clinical trials. Control Clin Trials 1986, 7(3):177-188

29. Andersen V, Ostergaard M, Christensen J, Overvad K, Tjonneland A, Vogel U: Polymorphisms in the xenobiotic transporter multidrug resistance 1 (MDR1) and interaction with meat intake in relation to risk of colorectal cancer in a danish prospective case-cohort study. BMC Cancer 2009, 9:407

30. Campa D, Butterbach K, Slager SL, Skibola CF, de Sanjose S, Benavente Y, Becker N, Foretova L, Maynadie M, Cocco P, et al: A comprehensive study of polymorphisms in the $A B C B 1, A B C C 2, A B C G 2, N R 112$ genes and lymphoma risk. Int J Cancer 2011, 131(4):803-812.

31. Campa D, Pardini B, Naccarati A, Vodickova L, Novotny J, Forsti A, Hemminki $K$, Barale $R$, Vodicka $P$, Canzian F: A gene-wide investigation on polymorphisms in the ABCG2/BRCP transporter and susceptibility to colorectal cancer. Mutat Res 2008, 645(1-2):56-60.

32. Gardner ER, Ahlers CM, Shukla S, Sissung TM, Ockers SB, Price DK, Hamada A, Robey RW, Steinberg SM, Ambudkar SV, et al: Association of the ABCG2 C421A polymorphism with prostate cancer risk and survival. BJU Int 2008, 102(11):1694-1699.
33. Hu LL, Wang XX, Chen X, Chang J, Li C, Zhang Y, Yang J, Jiang W, Zhuang SM: BCRP gene polymorphisms are associated with susceptibility and survival of diffuse large B-cell lymphoma. Carcinogenesis 2007, 28(8):1740-1744.

34. Korenaga $Y$, Naito K, Okayama N, Hirata H, Suehiro $Y$, Hamanaka $Y$, Matsuyama $\mathrm{H}$, Hinoda $\mathrm{Y}$ : Association of the BCRP C421A polymorphism with nonpapillary renal cell carcinoma. Int J Cancer 2005, 117(3):431-434

35. Muller P, Asher N, Heled M, Cohen SB, Risch A, Rund D: Polymorphisms in transporter and phase II metabolism genes as potential modifiers of the predisposition to and treatment outcome of de novo acute myeloid leukemia in Israeli ethnic groups. Leuk Res 2008, 32(6):919-929.

36. Semsei AF, Erdelyi DJ, Ungvari I, Kamory E, Csokay B, Andrikovics H, Tordai A, Csagoly E, Falus A, Kovacs GT, et al: Association of some rare haplotypes and genotype combinations in the MDR1 gene with childhood acute lymphoblastic leukaemia. Leuk Res 2008, 32(8):1214-1220.

37. Hahn WC, Weinberg RA: Modelling the molecular circuitry of cancer. Nat Rev Cancer 2002, 2(5):331-341.

38. Hediger MA, Romero MF, Peng JB, Rolfs A, Takanaga H, Bruford EA: The $A B C s$ of solute carriers: physiological, pathological and therapeutic implications of human membrane transport proteins introduction. Pflugers Arch 2004, 447(5):465-468.

39. Wang WY, Barratt BJ, Clayton DG, Todd JA: Genome-wide association studies: theoretical and practical concerns. Nat Rev Genet 2005, 6(2):109-118.

40. Conde L, Halperin E, Akers NK, Brown KM, Smedby KE, Rothman N, Nieters A, Slager SL, Brooks-Wilson A, Agana L, et al: Genome-wide association study of follicular lymphoma identifies a risk locus at 6p21.32. Nat Genet 2010, 42(8):661-664.

41. Slager SL, Rabe KG, Achenbach SJ, Vachon CM, Goldin LR, Strom SS, Lanasa MC, Spector LG, Rassenti LZ, Leis JF, et al: Genome-wide association study identifies a novel susceptibility locus at 6p21.3 among familial CLL. Blood 2011, 117(6):1911-1916.

doi:10.1186/1471-2407-12-383

Cite this article as: Chen et al:: The contribution of the ABCG2 C421A polymorphism to cancer susceptibility: a meta-analysis of the current literature. BMC Cancer 2012 12:383.

\section{Submit your next manuscript to BioMed Central and take full advantage of:}

- Convenient online submission

- Thorough peer review

- No space constraints or color figure charges

- Immediate publication on acceptance

- Inclusion in PubMed, CAS, Scopus and Google Scholar

- Research which is freely available for redistribution

Submit your manuscript at www.biomedcentral.com/submit
C) Biomed Central 